Federal Reserve Bank of Minneapolis

Research Department

\title{
RISK PREMIUMS IN THE TERM STRUCTURE: EVIDENCE FROM ARTIFICIAL ECONOMIES
}

\author{
David K. Backus, Allan W. Gregory, \\ and Stanley E. Zin \\ Working Paper 429 \\ First Draft: July 1986 \\ Revised: March 1989 \\ NOT FOR DISTRIBUTION \\ WITHOUT AUTHOR APPROVAL
}

\begin{abstract}
We compare the statistical properties of prices of U.S. treasury bills to those generated by a theoretical dynamic exchange economy with complete markets. We show that the model can account for neither the sign nor the magnitude of average risk premiums in forward prices and holding-period returns. The economy is also incapable of generating enough variation in risk premiums to account for rejections of the expectations hypothesis with treasury bill data. These conclusions add to the growing list of empirical deficiencies of the representative agent model of asset pricing.
\end{abstract}

Keywords: forward prices; holding-period returns; expectations hypothesis; autoregressive heteroskedasticity.

JEL Classification Numbers: 212, 313.

* Backus, Federal Reserve Bank of Minneapolis; Gregory, Queen's University; Zin, Carnegie Mellon University. We thank Nancy Horsmann for assistance with the CRSP tape and the National Science Foundation and Social Sciences and Humanities Research Council of Canada for financial support. We also thank Tom McCurdy, Gregor Smith, a referee, and the editors of this journal for comments on earlier drafts, and George Tauchen, whose work on artificial economies helped to motivate our own. Our computer programs (written in FORTRAN 77) are available on request.

The views expressed are those of the authors and not necessarily those of the Federal Reserve Bank of Minneapolis or the Federal Reserve System. This paper is preliminary and is circulated to stimulate discussion. It is not to be quoted without the permission of the authors. 


\section{Introduction}

One of the more firmly established facts of financial economics is that the expectations hypothesis of the term structure of interest rates cannot explain observed fluctuations in multiperiod bond returns: forward rates are not simply predictors of future spot rates. Viewed as predictors, forward rates consistently overestimate future spot rates, and the "forecast errors" are systematically related to variables that are known when the forecast is made. The consensus in the profession seems to be that forward rates contain, in addition to forecasts of future spot rates, risk premiums that change through time.

Risk premiums on forward contracts are not directly observable, but there are a number of pieces of evidence suggesting that they vary considerably over time. Consider the linear regression (error term omitted)

$$
r_{t+1}-r_{t+1}=a+b\left(r_{t}^{f}-r_{t}\right)
$$

where $r$ is the one-period spot rate of interest and $r^{f}$ is the one period ahead forward rate. Under the expectations hypothesis forward rates are market expectations of future spot rates, which implies the coefficient restrictions $a=0$ and $b=1$. The implicit alternative hypothesis is generally taken to be that the forward rate is the sum of the expected future spot rate and a risk premium. The evidence, presented in Fama (1984, table 4), is that neither restriction is supported by the data; related work by Startz (1982) and others is reviewed by Melino (1987) and Shiller and McCulloch (1987). Rejection of the first restriction, $a=0$, might be explained by a nonzero but constant risk premium, but rejection of the second requires, under the alternative, a risk premium that varies through time and is correlated with the forward premium, $r_{t}^{f}-r_{t}$.

We ask whether this interpretation of the evidence is consistent with a 
specific theory of the risk premium: the general equilibrium theory of asset pricing developed by Merton (1973), Lucas (1978), Breeden (1979), Brock (1982), and Cox, Ingersoll, and Ross (1985). Our approach, by focussing on the connection between prices and quantities, brings out different aspects of the theory than those emphasized in recent studies of prices alone by Brown and Dybvig (1986), Stambaugh (1986), and Gibbons and Ramaswamy (1986). The issue, to put it in terms of the empirical literature, is whether a numerical version of the theory can account for the variation in risk premiums implicit in rejections of the expectations hypothesis. Because risk premiums are not directly observable, the theory has been difficult to confirm or reject. Most of the evidence cited in its favor, including the regression test just described, consists of rejections of the expectations hypothesis. It has the same uncertain status as any alternative hypothesis in a statistical test: rejecting the null does not confirm the alternative. We examine the alternative hypothesis directly in a monetary version of the Mehra-Prescott (1985) economy. In the artificial economy we know exactly what risk premiums are at all times, and can determine the extent of their influence by comparing regressions with them and without. We cannot say whether time-varying risk premiums are the cause of rejections of the expectations hypothesis with real-world data, but we can say whether the model is capable of generating risk premiums that produce similar results in the theoretical economy.

In the following four sections we review the empirical record, build an artificial economy, and compare its statistical properties to those of postwar quarterly time series data for the United States. In Section 2 we survey empirical work on the term structure and report sample regressions with U.S. treasury bill prices. We use prices, rather than the more 
conventional rates, to provide a closer fit with the theory, but the choice makes little difference. Both prices and rates suggest that risk premiums are nonzero on average and vary over time.

In Section 3 we describe a monetary version of the Mehra-Prescott (1985) economy and derive its implications for prices of riskfree real and nominal discount bonds of different maturities. Two propositions summarize the behavior of risk premiums in this economy under fairly general conditions: the risk premium's sign is determined by the autocorrelation of two-period marginal rates of substitution, and its variability is highest at the short end of the maturity spectrum.

In Section 4 we use a parametric two-state example to illustrate two empirical anomalies: features of the data that are difficult to reconcile with the theoretical model. We show, first, that to generate average risk premiums as large in absolute value as those present in the treasury bill market, the coefficient of relative risk aversion must be at least 8 or 10 , values viewed by many as implausibly large. A similar anomaly is described for equity premiums by Mehra and Prescott (1985), and for holding-period yields on a variety of assets by Grossman, Melino, and Shiller (1987). A second difficulty, which has not to our knowledge been noted elsewhere, concerns the sign of the average risk premium. In the theoretical economy risk premiums are positive if and only if growth rates of consumption are negatively autocorrelated. Since quarterly consumption growth rates are virtually uncorrelated, the model cannot account for the positive average risk premiums apparent in the data.

We return to the variability of risk premiums in Section 5 . We argue there that the theoretical economy cannot generate sufficient variability to account for rejections of the expectations hypothesis without also generating 
implausible values for mean risk premiums. This is true even if some parameters, like the autocorrelation of consumption growth rates and the coefficient of relative risk aversion, are chosen, despite evidence to the contrary, to overcome the anomalies just noted. The analysis uses the theoretical economy to produce artificial time series of bond prices, with which we estimate and conduct diagnostic tests of regressions reported in studies with actual data. Using the artificial data we examine the influence of risk premiums on these results. We find that regression tests are unable to reject the expectations hypothesis with reasonable, or even some unreasonable, parameter values: the hypothesis $b=1$ in equation (1.1) is retained even in models with sizable risk premiums.

In short, the theory in its present form cannot explain the sign, the magnitude, or the variability of risk premiums observed at the short end of the term structure of interest rates. We conclude with a brief summary and a few remarks on methodology.

\section{Risk premiums in treasury bill data}

We begin by reviewing empirical work on the term structure and reporting sample statistics for quarterly U.S. treasury bill prices. We use prices rather than rates, because they fit more naturally into our theoretical environment.

The price of a k-period treasury bill or "bond" is denoted $\mathrm{q}_{\mathrm{kt}}$. Forward prices are defined by

$$
f_{k t} \equiv q_{k, t+1} / q_{k t}, \quad k=1,2, \ldots .
$$

These prices are related to interest rates by

$$
\begin{aligned}
q_{1 t} & \equiv 1 /\left(1+r_{1 t}\right) \\
f_{k t} & \equiv 1 /\left(1+r_{k t}^{f}\right),
\end{aligned}
$$


where $r_{1 t}$ is the one-period spot rate and $r_{k t}^{f}$ is the k-period-ahead forward rate. The (gross) holding-period return -- the return from holding a kperiod bond for one period -- is

$$
h_{k t} \equiv q_{k-1, t+1} / q_{k t}, \quad k=2,3, \ldots .
$$

For $k=1$ the holding-period return is just one plus the one-period spot rate of interest. The excess return on a k-period bond is $h_{k t}-h_{1 t}$.

Both forward prices and holding-period returns can be viewed as combinations of forecasts and risk premiums. With respect to the former, we define the risk premium, $f p$, on a k-period forward contract by

$$
f p_{k t} \equiv E_{t} q_{1 t+1}-f_{k t} \text {, }
$$

the difference between the forward price and the expected future spot price. The operator $E_{t}$ denotes the expectation conditional on the date-t information set, which we assume includes the past and present values of spot and forward prices. Note that (2.3) allows explicitly for the possibility that the risk premium varies with $t$. The sign convention means that the risk premium is positive when the forward rate exceeds the expected future spot rate, and the reverse for prices. Similarly we define the risk premium, hp, implicit in the holding-period return $h_{k t}$ as the expected excess return:

$$
h p_{k t} \equiv E_{t} h_{k t}-h_{1 t} \text {. }
$$

It, too, can vary with time.

In Table 2.1 we report sample moments for selected treasury bill prices and returns. The time interval is a quarter, so $\mathrm{q}_{1 \mathrm{t}}$ is the price of a three-month treasury bill. Fama (1984) reports similar statistics on a monthly basis. The average price of a three-month treasury bill over the sample period is 0.98432 , which corresponds to an interest rate of 1.59 percent per quarter. The last two columns give us information about the two 
risk premiums. The fourth variable, $q_{1 t+1}-f_{1 t}$, consists of a forecast error plus a risk premium. If forecast errors have zero mean conditionally, then they do unconditionally as well, and the sample mean of this variable is an estimate of the mean risk premium over the sample period. We see that the mean risk premium is small, but positive and statistically significant. And since forecast errors are serially uncorrelated, risk premiums must be negatively autocorrelated, in the sample, to account for the insignificant negative autocorrelation in the table. The estimated autocorrelation should understate (in absolute value) that of the risk premium, since it combines the time dependence of the risk premium with that of a serially uncorrelated forecast error. The last variable in the table is also the sum of a risk premium and a forecast error and its properties are similar.

There is evidence, too, that the risk premium is not only nonzero, but varies substantially over time. Most of this work on the term structure, surveyed recently by Melino (1987) and Shiller and McCulloch (1987), has been oriented around the expectations hypothesis. Initially this was understood to mean that risk premiums are zero, but in light of evidence like Table 2.1 it was amended to mean simply that risk premiums are constant: they do not vary with the state of the economy. Even so, a large empirical literature has found the hypothesis wanting. As Shiller and McCulloch (1987, p 61) remark, "empirical work has produced consensus on little more than that the ... expectations [hypothesis] ... can be rejected."

Most of the evidence against the expectations hypothesis is based on regressions relating forward and spot prices to other variables. In the most popular version, the difference between forward prices (or rates) and corresponding future spot prices (rates) is examined for predictability. If the expectations hypothesis is valid this difference is, except possibly for 
a nonzero mean, a pure forecast error, and should not be predictable by anything in the current information set. Several tests are constructed by choosing different variables from this information set. The simplest is based on the regression (error term omitted)

$$
q_{1 t+1}-f_{1 t}=a .
$$

Since lagged forecast errors are part of the information set, autocorrelation of residuals from (2.4) is evidence against the expectations hypothesis. Other tests use regressions of the form

$$
q_{1 t+1}-f_{1 t}=a+b x_{t}
$$

where $x_{t}$ is a subset of the information available at date $t$. A test of the coefficient restriction $b=0$ is a test of the expectations hypothesis. The forward premium, $f_{1 t}-q_{1 t}$, is a common choice for $x_{t}$. This regression often appears in the literature in the form

$$
q_{1 t+1}-q_{1 t}=a+(b+1)\left(f_{1 t}-q_{1 t}\right)
$$

which is (2.5) with the forward premium added to both sides. Since least squares is invariant to such linear transformations the implied estimator of $\mathrm{b}$ is identical to that in (2.5), but it provides a useful interpretation of the parameter. If $\mathrm{b}$ is nonzero we can reject the expectations hypothesis, but for all values except -1 the forward premium is still helpful in predicting future changes in spot prices. A second variant of (2.5) uses the lagged dependent variable as $\mathrm{x}$ which, under the expectations hypothesis, is simply the lagged forecast error plus a constant. There is no presumption in any of these equations, even under the expectations hypothesis, that the errors are homoskedastic.

The same kinds of tests have been applied to excess holding-period returns. Examples are the regressions 


$$
\begin{gathered}
h_{2 t}-h_{1 t}=a \\
h_{2 t}-h_{1 t}=a+b x_{t}
\end{gathered}
$$

for some choice of $\mathrm{x}$. Below we use both the forward premium and the lagged dependent variable. The expectations hypothesis requires that the residuals be serially uncorrelated and the coefficient, b, equal zero. Again, the errors need not be homoskedastic.

Estimates of equations (2.4) to (2.8) have been remarkably uniform across studies and time periods. The constants in (2.4) and (2.7) are usually small, as we saw in Table 2.1, but significantly positive (Roll, 1970, Chapter 5; Fama, 1976, Table 1). Tests of the hypothesis $b=0$ in equations (2.5) and (2.8) frequently reject, especially when the independent variable is the forward premium. Numerical estimates of $b$ in this case differ across studies. In Fama's (1984, Table 4) study of treasury bill returns at monthly intervals, reported in the form of equation (2.6), the estimates of $b+1$ are between. 11 and .46 for the complete sample. This suggests that although the expectations hypothesis can be rejected, the forward premium helps to predict future changes in spot rates, at least over short forecast horizons. Shiller, Campbell, and Schoenholtz, (1983, Table 3, rows 1-5) estimate equation (2.6) with quarterly treasury bill returns and report similar estimates. The residuals in these regressions exhibit autoregressive conditional heteroskedasticity (see Engle, Lilien, and Robins, 1987).

These features are illustrated in Table 2.2 for quarterly U.S. treasury bill prices. We report the six regressions mentioned earlier and subject the residuals to two kinds of analysis. The first is the Durbin-Godfrey LM test for serial correlation; we report marginal significance levels for tests of first and fourth-order time-dependence. The second is Engle's (1982) LM test 
for autoregressive conditionally-heteroskedastic (ARCH) errors, again for orders one and four. We also report results of Wald tests of the hypotheses $a=b=0, b=0$, and $b=-1$, all based on heteroskedasticity-consistent standard errors (White, 1980). Since the data are far from homoskedastic, this correction is essential. None of the test statistics has precisely the distribution used to compute tail probabilities, even under the null, since they are based on maintained hypotheses that need not be true. The Durbin-Godfrey tests, for example, are based on independent normal errors, so they may be sensitive to autoregressive conditional heteroskedasticity as well as autocorrelation. Nevertheless, they provide useful information beyond that given by regression coefficients and standard errors.

In Table 2.2 both the forward-spot differential and the ex post holding premium have small, positive means, as we know from Table 2.1. The value of b is significantly negative in the forward premium regressions. The dependent variables are negatively autocorrelated but the estimated coefficient is not significant. The residuals in all regressions indicate serial correlation, especially of the fourth order, and of autoregressive conditional heteroskedasticity. The hypotheses $a=b=0, b=0$, and $b=-1$ are all rejected by the data in the forward premium regressions. Thus the expectations hypothesis is rejected while the ability of the forward premium to forecast future changes in spot prices is upheld. The nominal sizes of these tests are probably overstated, given the serial correlation and heteroskedasticity in the residuals, but it is hard to avoid the conclusion that the expectations hypothesis is contradicted by the data. Evidence from monthly data (Fama, 1984) is even stronger.

The regressions also provide direct estimates of the variability of risk premiums. Consider the forward risk premium, $f p_{1}$. Equation (2.3) implies 


$$
q_{1 t+1}-f_{1 t}=f p_{1 t}+\varepsilon_{t+1}
$$

where $\varepsilon_{t+1}$ is a forecast error with conditional and unconditional mean zero. Hence

$$
\operatorname{Var}\left(q_{1 t+1}-f_{1 t}\right)=\operatorname{Var}\left(f p_{1 t}\right)+\operatorname{Var}\left(\varepsilon_{t+1}\right)
$$

Since the risk premium can be predicted from date $t$ information but the forecast errors cannot, an estimated lower bound on the variability of the forward risk premium is the variability of the fitted values in any of the regressions explaining $\mathrm{q}_{1 \mathrm{t}+1^{-\mathrm{f}_{1}}}$. In the second regression of Table 2.2 the implied standard deviation is 0.00157; see Startz (1982) for a similar calculation with monthly data. An analogous exercise yields 0.00164 as an estimated lower bound on the standard deviation of the holding premium. In both cases the lower bounds are of the same order as, and slightly larger than, the estimated mean risk premium, so the variability is large in that sense. These estimated lower bounds are subject to sampling variability, but they help to quantify the extent of variation in risk premiums present in the data.

\section{A theoretical economy}

The question we have posed for ourselves is whether the behavior of bond prices in general, and the variability of risk premiums in particular, is consistent with the general equilibrium pricing theory of Merton (1973), Lucas (1978), Breeden (1979), Brock (1982), and Cox, Ingersoll, and Ross (1985). Our version of this theory is a monetary extension of Mehra and Prescott (1985), a stationary, recursive, pure-exchange version of an ArrowDebreu economy. In this economy a stochastic endowment of a single commodity is consumed by a single, representative agent, whose preferences are additively separable over time and obey the expected utility axioms. With 
quantities exogenous, the equilibrium allocation is determined by supply. Relative prices of dated, state-contingent claims are derived from marginal rates of substitution. Prices of composite assets, like riskfree bonds, are computed by combining the relevant contingent claims. Nominal claims, and implicitly money, are introduced toward the end of the section. We derive prices of riskfree bonds of different maturities, and use them to define forward prices, holding-period returns, and risk premiums.

The size of the endowment each period is described by a stationary Markov chain in growth rates. Output, $y_{t}$, evolves according to

$$
y_{t+1}=x_{t+1} y_{t} \text {, }
$$

and the distribution of its "rate of growth," $x_{t}$, depends only on its previous rate of growth. The state of the economy at date $t$ is known to the representative agent and is described completely in the real economy by the state, $s_{t} \equiv\left(y_{t}, x_{t}\right)$. As in Mehra and Prescott, growth rates take on a finite number of values, denoted $\lambda_{i}$. In principle this is not very restrictive, and the gain in computational simplicity is considerable. The stochastic behavior of output is characterized by a matrix $\Pi$ of transition probabilities for growth rates, with typical element

$$
\pi_{i j} \equiv \operatorname{Prob}\left(x_{t+1}=\lambda_{j} \mid x_{t}=\lambda_{i}\right) \text {. }
$$

Probabilities of events more than one period in the future are computed from powers of $\Pi$ :

$$
\operatorname{Prob}\left(x_{t+k}=\lambda_{j} \mid x_{t}=\lambda_{i}\right)=\left[\Pi^{k}\right]_{i j}
$$

These and other features of Markov chains are described in Feller (1968, ch XV) and Isaacson and Madsen (1976).

The stochastic endowment is consumed by a representative agent whose preferences are characterized by the expected utility function, 


$$
U=E_{t} \sum_{k=0}^{\infty} \beta^{k} u\left(c_{t+k}\right) \text {, }
$$

where $E_{t}$ denotes the expectation conditional on the histories as of date $t$ of all variables in the economy. With the Markov structure, this is equivalent to conditioning on $s_{t}$ alone. To maintain stationarity of prices in a growing economy we specify further that $U$ is homothetic. With additive separability over time and states this implies the class of power subutility functions, $u(c)=\left[c^{1-\alpha}-1\right] /(1-\alpha)$. The parameter $\alpha \geq 0$ governs both risk aversion and the substitutability of consumption over time.

An equilibrium in this economy is a set of state-contingent prices for which consumption equals the endowment at all dates and in all states. Relative prices are computed by equating them to marginal rates of substitution evaluated at exogenous equilibrium quantities. If the current state is $\left(y_{t}, \lambda_{i}\right)$, then the relative price of one unit of the commodity next period if state $j$ occurs to one unit now is

$$
\pi_{i j} \beta u^{\prime}\left(y_{t+1}\right) / u^{\prime}\left(y_{t}\right)=\pi_{i j} \beta u^{\prime}\left(\lambda_{j} y_{t}\right) / u^{\prime}\left(y_{t}\right)
$$

a function of the current state. With power utility this price is $\pi_{i j} \beta \lambda_{j}^{-\alpha}$, which depends, through the transition probability, on the growth rate $\lambda_{i}$, but not the level of output. Our interest lies in prices of "riskfree" assets. We examine both real bonds, which yield one unit of the commodity in some future period in all states, and nominal bonds, which yield one unit of money. Prices in both cases are computed by summing prices of pure contingent claims. Consider real bonds first. The price, $q_{1 t}$, of a one-period, date-t, riskfree, discount bond, which delivers one unit of the commodity at date $t+1$ in all states, is

$$
q_{1 t}=\Sigma_{j} \pi_{i j} \beta u^{\prime}\left(y_{t+1}\right) / u^{\prime}\left(y_{t}\right)
$$




$$
=E_{t} \pi_{i j} \beta u^{\prime}\left(y_{t+1}\right) / u^{\prime}\left(y_{t}\right) .
$$

If we define $m_{t+1} \equiv \beta u^{\prime}\left(y_{t+1}\right) / u^{\prime}\left(y_{t}\right)$, we can express this more compactly as $q_{1 t}=E_{t} m_{t+1}$. With power utility $m_{t+1}=\beta x_{t+1}^{-\alpha}$, so that $m$ depends on the rate of growth of output but not its level. The bond price is simply a function of the current growth rate, say $q_{1 t}=q_{1}\left(\lambda_{i}\right)$ for $x_{t}=\lambda_{i}$.

Prices of long-term bonds are derived the same way. A k-period real bond, yielding one unit of the commodity $k$ periods hence in all states, is priced according to

$$
\begin{aligned}
q_{k t} & =E_{t} \prod_{i=1}^{k} m_{t+i} \\
& =E_{t} m_{t+1} q_{k-1, t+1} .
\end{aligned}
$$

Since the distribution over future m's depends only on the current growth rate, this defines pricing functions $q_{k}\left(\lambda_{i}\right)$, for $k=2,3, \ldots$.

Implicit in these pricing functions are analogous functions for forward prices and risk premiums. The forward pricing function is, by analogy with equation (2.1),

$$
f_{k}\left(\lambda_{i}\right)=q_{k+1}\left(\lambda_{i}\right) / q_{k}\left(\lambda_{i}\right)
$$

The risk premium, $f p$, defined by equation (2.3), can also be written

$$
f p_{k t}=-\operatorname{Cov}_{t}\left\{\prod_{i=1}^{k} m_{t+i}, q_{1 t+k}\right\} / q_{k t},
$$

where $\mathrm{Cov}_{t}$ is the conditional covariance operator. Since the distribution with which the covariance is computed depends on the current state, the forward premium is a function of the state and is, in that sense, time varying.

The behavior of bond prices, returns, and risk premiums depends on the parameters of the model: $\alpha, \beta, \Pi$, and the $\lambda$ 's. Two useful features of this relationship are summarized in the following propositions. 
Proposition 1. If either (i) the representative consumer is risk-neutral $(\alpha=0)$ or (ii) marginal rates of substitution, $m$, are independent, then forward premiums fp and holding premiums hp are zero in all states.

Proof. If the representative consumer is risk neutral then $m=\beta$ in all states. Bond prices, forward prices, and holding-period yields are constant and risk premiums are zero in all states. If, on the other hand, marginal rates of substitution are independent, as they will be in our economy if growth rates are independent, the price of a k-period bond is simply the product of expected future spot prices:

$$
q_{k t}=E_{t} \prod_{i=1}^{k} m_{t+i}=\prod_{i=1}^{k} E_{t} m_{t+i}=\prod_{i=1}^{k} E_{t} q_{1, t+i-1} .
$$

Then forward prices equal expected future spot prices and risk premiums on forward contracts are zero. The expected one-period yield on an n-period bond is, by the same argument,

$$
E_{t} h_{k t}=E_{t} \prod_{i=1}^{k-1} m_{t+i} / E_{t} \prod_{i=1}^{k} m_{t+i}=1 / E_{t} m_{t+k} .
$$

Since the transition probabilities do not depend on the date, $E_{t} m_{t+1}=E_{t} m_{t+2}$ $=\ldots=E_{t} m_{t+k}$. Holding-period returns are equal on bonds of all maturities and holding premiums are zero.

Proposition 1 tells us that with serially uncorrelated marginal rates of substitution bond prices in the theoretical economy behave according to the expectations hypothesis. To generate the nonzero time varying risk premiums we observe in U.S. treasury bill market, the conditional distribution over future marginal rates of substitution must depend on the current state. Furthermore, the sign of the risk premium is determined by the form of that dependence: risk premiums on forward contracts are positive (negative) if marginal rates of substitution are negatively (positively) autocorrelated. 
Beyond that, there is little we can say without placing more structure on the model. We can, however, show that forward risk premiums converge in the following sense.

Proposition 2. If the Markov chain in growth rates is ergodic, then as $k$ approaches infinity the forward pricing function $f_{k}(\lambda)$ converges to a constant, $f$, which does not depend on $\lambda$.

Proof. Consider the pricing functions for bonds. In state i, the price of a 1-period bond is $\Sigma_{j} \pi_{i j} \beta \lambda_{j}^{-\alpha}$. We can express this more compactly as $\Sigma_{j} b_{i j}$, where $b_{i j} \equiv \pi_{i j} \beta \lambda_{j}^{-\alpha}$ defines implicitly a matrix B. Similarly the price of a two-period bond is

$$
\Sigma_{j} \Sigma_{k} \pi_{i j} \pi_{j k} \beta^{2} \lambda_{j}^{-\alpha} \lambda_{k}^{\alpha}
$$

or $\sum_{j} b_{i j}^{(2)}$, where $b_{i j}^{(2)}$ denotes the $i j-t h$ element of $B^{2}$. More generally the price of a k-period bond in state $i$ can be expressed $\Sigma_{j} b_{i j}^{(k)}$. Since the Markov chain is ergodic, the Perron-Frobenius theorem guarantees that the dominant eigenvalue of $B$ is positive and that any positive vector operated on by powers of B will eventually approach the associated eigenvector and grow at the rate of this eigenvalue. Now consider the k-period forward pricing function, the ratio of $k+1$-period to $k$-period bond pricing functions. As $k$ gets large this converges to the dominant eigenvalue of $\mathrm{B}$ regardless of the current state.

The intuition behind this result is that forward contracts in an ergodic economy look alike for long horizons. Each such contract specifies a payment of $f$ in, say, period $t+k$ and receipt of 1 in the following period, regardless of what states occur in those periods. For an ergodic chain the distribution over these states is, for large $\mathrm{k}$, the long-run equilibrium distribution of the Markov chain and does not depend on the current state. 
An immediate corollary of Proposition 2 is that forward risk premiums also converge: since the Markov chain is ergodic the expected future spot price, $E_{t} q_{1 t+k}$, converges to the unconditional mean of $q_{1}$ and the forward premium, $f p_{k}\left(\lambda_{i}\right)$, converges to the difference. Of course if forward prices converge then the yield to maturity on a long bond, the geometric mean of forward prices, also converges. It is not true, however, that holding premiums converge in a similar manner. Instead the distribution over holding premiums converges, so that holding premiums on two long bonds of different maturities are similar functions of the current state.

Nominal bond pricing can be handled in much the same way as real bond pricing. The primary issue is how we get money, and therefore nominal bonds, into the economy. To be concrete about this, we imagine following Lucas (1982) in using cash-in-advance constraints. If monetary growth rates are described by a Markov chain, then the equilibrium will be characterized by a Markov chain in consumption growth rates and inflation. The state then consists of three variables -- output, its growth rate, and inflation -which we can describe by a Markov chain in the latter two. The only restriction on the process is that nominal bond prices, to be defined shortly, cannot exceed one in any state (nominal interest rates are nonnegative). This theoretical structure is described more completely in Sargent (1987, ch 5) and Backus and Kehoe (1987, section 5).

Consider the currency price of a one-period nominal bond: a claim to one unit of currency next period in all states. The value in date-t marginal utility units of one dollar in period $t+1$ is $\beta E_{t}\left[u^{\prime}\left(c_{t+1}\right) / p_{t+1}\right]$, where $p_{t+1}$ is the (state-contingent) currency price of one unit of the commodity. Similarly, the value of one unit of currency at date $t$ is $u^{\prime}\left(c_{t}\right) / p_{t}$. The equilibrium price of a one-period nominal bond is the ratio. 


$$
q_{1 t}=E_{t}\left\{\left[\beta u^{\prime}\left(y_{t+1}\right) / u^{\prime}\left(y_{t}\right)\right]\left[p_{t} / p_{t+1}\right]\right\} \equiv E_{t} n_{t+1},
$$

with the obvious definition of $n_{t+1}$, the nominal marginal rate of substitution. Prices of multiperiod nominal bonds are, by analogy with equation (3.2),

$$
\begin{aligned}
q_{k t} & =E_{t} \prod_{i=1}^{k} n_{t+i} \\
& =E_{t} n_{t+1} q_{k-1, t+1} .
\end{aligned}
$$

From these we compute forward prices and holding-period yields as before.

From this point on, the mathematical treatment of real and nominal bonds is almost identical. As in Proposition 1, risk premiums on nominal bonds are driven by persistence in the marginal rate of substitution, given here by $n$ : if there is no autocorrelation in $n$, risk premiums are zero and the expectations hypothesis holds. Risk neutrality, however, is no longer sufficient to eliminate "risk premiums": with $\alpha=0, \mathrm{~m}$ is constant as before, but fluctuations in the rate of inflation may lead to systematic differences between forward and expected future spot prices. The same effect has been noted in the pricing of forward foreign exchange contracts, which are also expressed in nominal terms.

Proposition 2 changes in the natural way: forward prices converge if the Markov chain for consumption growth rates and inflation together is ergodic. The theory is the same, but as a practical matter the assumption of ergodicity may be less plausible with nominal variables than with real ones.

\section{A two-state example}

In this section we specialize the model and compare its properties to those of U.S. time series. Using a two-state example we point out two features of U.S. data that are not consistent with quantitative properties of 
the theory.

We assume, first, that the transition matrix has elements

$$
\pi_{i j}=(1-\theta) \pi_{j}+\theta \delta_{i j}
$$

where $\delta_{i j}=1$ if $i=j, 0$ otherwise; $\pi_{j} \geq 0$; and $\Sigma_{j} \pi_{j}=1$. Barton, David, and Fix (1962) refer to this parameterization as "simple persistence." Clearly all the transition probabilities must be nonnegative, which places restrictions on the range of $\theta$. In the two-state case (4.1) places no restrictions on the form of the transition matrix, but it does lead to a useful interpretation of the parameters. When all transition probabilities are positive, conditional probabilities converge to a unique invariant, or long-run equilibrium, distribution, with probability $\pi_{j}$ of being in state $j$ in the distant future. The parameter $\theta$ governs persistence: if $\theta$ is zero, states are independent over time; positive and negative values indicate positive and negative autocorrelation of states. From Proposition 1 we know that nonzero values of $\theta$ are a prerequisite for nonzero risk premiums.

The preference parameters, $\alpha$ and $\beta$, enter the calculations through the marginal rate of substitution. To make this as simple as possible, we begin by considering an economy in which the price level, $p$, is constant. Then if consumption growth rates take on two values, $\lambda_{1}$ and $\lambda_{2}$ say, the marginal rate of substitution, $n$, assumes the values $\mu_{1}$ and $\mu_{2}$ defined by $\mu_{j}=\beta \lambda_{j}^{-\alpha}$. Larger values of $\alpha$, indicating greater risk aversion, lead, in general, to greater variation in $\mathrm{n}$. The discount factor, $\beta$, is simply a scale factor.

Now consider bond prices when the equilibrium distribution is symmetric, so that the long-run probability of each state is one half. We can express the values of $n$ in the two states as $(a-b)$ and $(a+b)$, where $a$ and $b$ are, respectively, the mean and standard deviation of $n$. Bond prices, forward prices, and holding-period returns can then be computed using equations 
(3.2), (3.3), and (2.2). Their values, which can be found by tedious but straightforward calculation, are summarized in Table 4.1. Note, in particular, that the one-period forward premium in both states is approximately

$$
-\theta\left(1-\theta^{2}\right) b^{2}
$$

since three-month bond prices are close to one. (The range in our sample is 0.962 to 0.995.) Thus the size of the risk premium in our example depends in a nonlinear way on $\theta$ and is proportional to the variance of $n$. As we noted in Proposition 1, the risk premium is zero when $\theta=0$.

Our objective is to compare the theory, and the two-state example in particular, with U.S. data on consumption growth rates and treasury-bill prices. In Table 4.2 we report quarterly growth rates of consumption and consumption price deflators for the postwar period. From the mean, standard deviation, and autocorrelation of the consumption growth rate we can get an idea of what bond prices would be like in a noninflationary environment. For illustration we use the two-state distribution, $x=1.005 \pm 0.010$, which has a slightly larger standard deviation than we observe in U.S. nondurables consumption.

We noted that the risk premium is approximately $\theta\left(1-\theta^{2}\right) b^{2}$. The first two terms have a maximum (in absolute value) of 0.385 at $|\theta|=1 / \sqrt{3} \cong 0.58$. For the model to generate a risk premium of 0.0012 we need a standard deviation, $b$, of the marginal rate of substitution of at least 0.056 . If there is no inflation, the observed variance of $\mathrm{x}$ tells us what $\alpha$ must be for the model to match the data. As we vary $\alpha$ from 1 to 40 , choosing $\beta$ so that the mean of $\mathrm{n}$ in each case is 0.99 , this changes $b$, the standard deviation of $n$, as follows: 


\begin{tabular}{cccccc} 
& \multicolumn{5}{c}{$\alpha=$} \\
$\mu_{1}$ & 1 & 2 & 5 & 10 & 40 \\
$\mu_{2}$ & 0.9802 & 0.9703 & 0.9408 & 0.8918 & 0.6155 \\
$\mathrm{~b}$ & 0.9998 & 1.0097 & 1.0392 & 1.0882 & 1.3645 \\
& 0.0099 & 0.0197 & 0.0492 & 0.0982 & 0.3745.
\end{tabular}

To get risk premiums as large as those observed in the U.S. treasury bill market $\alpha$ must be at least 7 or 8 , and larger for different values of $\theta$. Inflation modifies the calculations slightly, and in principle volatility of the price level could account for some of the required volatility of $n$. The last section of Table 4.2 makes it clear, however, that a large value of $\alpha$ is still necessary to generate a sufficiently large variance in the marginal rate of substitution. Nominal marginal rates of substitution are not much more variable than real ones in postwar U.S. data.

We conclude that the model is inconsistent with consumption data for modest values of the risk aversion parameter. Mehra and Prescott (1985), who studied the risk premium on equity, interpret a similar result as evidence against the model. Although there has been debate on this issue, most econometric evidence points to smaller values of $\alpha$ than are required to reconcile the model with the data. Hansen and Singleton (1982, 1983), for example, using a theoretical framework similar to ours, estimate that $\alpha$ lies between one and two.

A second anomaly concerns the persistence parameter, $\theta$. We noted that the model generates risk premiums and autocorrelated prices only if there is autocorrelation in marginal rates of substitution. Further, the sign of $\theta$ determines the sign of the risk premium, so that a positive risk premium can only be generated in the artificial economy when $\theta$ is negative -- that is, when marginal rates of substitution are negatively autocorrelated. In our economy marginal rates of substitution are simple functions of consumption 
growth rates. The evidence for such autocorrelation in quarterly U.S. consumption growth rates is just not there. The estimates in Table 4.2 are typically positive and not significantly different from zero. This property is not altered by accounting for the nonlinearity introduced by risk aversion, the additional randomness attributable to inflation, or even the particular sample period chosen.

These two discrepancies between theory and data appear to be robust to both small modifications of the theory and reinterpretations of the evidence. With regard to risk aversion, Epstein and Zin (1987a) suggest that an alternative class of preferences in which risk aversion and intertemporal substitution, both determined by $\alpha$ in our economy, are independent, may generate more plausible asset prices with modest degrees of risk aversion. Subsequent empirical work by Epstein and Zin (1989b) and Hansen and Jagannnathan (1988) indicates, however, that this extension of the class of preferences is not sufficient to account for the dynamic behavior of bond and equity prices.

With regard to serial correlation in marginal rates of substitution, two considerations arise. The first is time aggregation. The consumption and price level data used in Table 4.2 are averages over a quarter, while the treasury bill prices used in Tables 2.1 and 2.2 are measured at points in time. In the theory both are measured at the same point in time, but since point-sampled consumption is not available we used time-averaged quarterly data. It is difficult to think of a situation in which time aggregation is innocuous with respect to the serial correlation properties of the data, and Ermini (1988) and Heaton (1988) show that at monthly intervals consumption growth rates are negatively autocorrelated. This might imply negative autocorrelation in quarterly consumption growth rates for point-sampled data, 
but a more plausible explanation is measurement error in the levels of the monthly series.

A different direction of attack on the lack of autocorrelation in the data is to posit modifications to the economy, like durable goods or habit formation, that generate serially correlated marginal rates of substitution from serially uncorrelated growth rates of expenditures. Dunn and Singleton (1986), for example, estimate a consumption-based model for the term structure with durable goods. However, this produces positive, not negative, autocorrelation of marginal rates of substitution. Constantinides' (1988) model of habit persistence can produce negative autocorrelation in marginal rates of substitution even when growth rates of consumer expenditures are independent.

\section{Risk premiums in artificial data}

In the last section we examined the model's ability to match some of the sample moments of treasury bill data, an exercise in the spirit of Mehra and Prescott's study of the equity premium. Here we return to the issue noted at the start: can the model account for rejections of the expectations hypothesis with U.S. treasury bill data? This requires not only a nonzero risk premium, but one that varies over time, so the issue is whether this variation is consistent with the theory and the parameter values suggested in the previous section. We also examine the model's ability to reproduce the autoregressive conditional heteroskedasticity (ARCH) found in regressions with historical data.

We begin by reestimating the treasury bill regressions of Table 2.2 with data from our artificial economy. Since the forward-price and holding-period-return regressions are almost identical, we report only the 
former. In each experiment we report summary statistics from one thousand replications of two hundred observations each. The initial state is selected at random (using NAG pseudo-random number generator G05CAF) from the equilibrium distribution, and succeeding states are drawn from the distribution described by the appropriate row of the transition matrix. We use the simple persistence parameterization, equation (4.1), unless noted otherwise. Values for nominal marginal rates of substitution in each state are entered directly.

In experiment 1 , reported in Table 5.1, the mean and standard deviation of $\mathrm{n}$ are taken from Table 4.2 with $\alpha=10$. We set $\theta=-0.3$, which provides the required negative serial correlation, and set $\pi_{1}=\pi_{2}=1 / 2$ (a symmetric equilibrium distribution). The nonzero value of $\theta$ has little empirical support, but without it the model is doomed to failure from the start. We view the exercise as telling us whether modifications of the economy designed to induce negative serial correlation in marginal rates of substitution are likely to be successful in accounting for variations in risk premiums as well as nonzero means. The mean risk premium in this economy is 0.00193 , which is about 30 percent larger than we saw for treasury bill data.

In fact the model economy with these parameter values does not have enough variability in the risk premium to account for rejections of the expectations hypothesis. There is ample evidence of nonzero risk premiums, but Wald tests of the expectations hypothesis $b=0$ and LM tests for autoregressive and ARCH errors have little power. The numbers of rejections for 5 percent tests are not much different from 50, which is what we expect from chance alone. The slight differences may, in fact, be due to sampling variability in our Monte Carlo experiment: a 95 percent confidence interval around 50 is approximately $[36,64]$. The hypothesis $b=-1$, that the forward 
premium has predictive power for changes in spot prices, is rejected overwhelmingly in all 1000 replications, a feature that recurs in all our experiments. Table 5.2 describes a single draw from the experiment in the same format as Table 2.2.

The assumption in experiment 1 of a symmetric equilibrium distribution turns out to be extremely restrictive. With this specification we virtually guarantee that the risk premium is constant and that forecast errors are homoskedastic. In the notation of Section 4, the risk premium on forward contracts is $-\theta\left(1-\theta^{2}\right) b^{2} / q_{1}$, where $b$ is the standard deviation of the marginal rate of substitution. Unless the one-period bond price has a huge variance, which it does not, the variance of the risk premium is too small to cause difficulties for the expectations hypothesis. In experiment 1 its standard deviation is 0.00005 , which is 2 percent of its mean and just 3 percent of the estimated lower bound of the standard deviation in U.S. treasury bill data. The symmetric distribution also rules out ARCH errors. The conditional variance of the one-period forecast error, $q_{1 t+1}-E_{t} q_{1 t+1}$, depends in general on the state, but when the equilibrium distribution is symmetric it is constant at $\theta^{2}(1-\theta)^{2} b^{2}$. Similar propositions hold approximately for holding premiums.

The clear implication is that we cannot generate realistic data with a symmetric equilibrium distribution in the two-state version of the economy. Since this choice is arbitrary we proceed to experiment with alternatives. In the first alternative, labelled experiment 2 , we change the equilibrium distribution slightly to $\left(\pi_{1}, \pi_{2}\right)=(0.6,0.4)$, with the same mean and standard deviation for $\mathrm{n}$ as experiment 1 . The mean risk premium is still 0.00193 , but its standard deviation rises to 0.00029 . The results are reported in Tables 5.3 and 5.4, and the outcome is somewhat closer to what we see in treasury 
bill data. Regressions with the risk premium (the odd-numbered equations) reject the joint hypothesis $a=b=0$ more of ten than without. Tests for $b=0$, however, reject about 5 percent of the time whether or not the risk premium is included, which is consistent with a time-invariant risk premium. We also see very little evidence of serial correlation. The test for first-order ARCH, on the other hand, rejects close to 50 percent of the time whether or not the risk premium is included. The same features are apparent in sample regressions from the experiment, shown in Table 5.4.

These two experiments together suggest that risk premiums in the artificial economy do not vary enough, or in the right manner, to explain econometric rejections of the expectations hypothesis. Our two experiments have this property, and reasonable changes in parameter values are unable to reverse it. More highly skewed equilibrium distributions, for example, increase the variability of the risk premium, but not enough to produce frequent rejections of $b=0$. Alternatively, if we increase $\alpha$, lowering (the absolute value of) $\theta$ at the same time to maintain the mean value of the risk premium, or the converse, the results change very little from those of Table 5.3. We need a large value of $\alpha$ to produce large risk premiums, and a large value of $\theta$ to make them predictable, as the regression results suggest they are. If we do both, raising $\alpha$ to 20 and $\theta$ to -0.5 , we can reject the expectations hypothesis easily, but with a mean risk premium of 0.01080 , almost 8 times larger than we see in U.S. bond data. See Supplementary Table 1.

Another example of an extreme experiment, which may be loosely associated with the peso problem, is described in Tables 5.5 and 5.6. In this experiment we have specified a three-state economy in which two similar states alternate with a third. There is strong positive persistence between 
the two similar states, as a group, and the unusual third state, but negative persistence between the two similar states themselves. We think of it as illustrating the possibility of a change in regime, from say low to high inflation. The change has a small probability conditional on being in the other regime, but is very persistent once the change occurs. In this case there is strong evidence of serial correlation and the coefficient restrictions are frequently rejected. Both are caused by the risk premium: the even-numbered experiments reject roughly five percent of the time.

The failure of experiments 1 and 2 , and modifications of them, to account for rejections of the expectations hypothesis can be traced directly to lack of variability in the risk premium. In Table 5.7 we report the mean and standard deviation of the forward risk premium for each of the three experiments and for two supplementary experiments (reported in Supplementary Tables 1 and 2). The first supplementary experiment is the one just described, with extreme values of $\alpha$ and $\theta$. The other is due to Reitz (1988), who proposed it as a solution to the equity premium puzzle. Only the experiment with extreme parameter values has as much variation in the risk premium as we estimate there is in the data, and that has a mean risk premium almost 8 times as large as we observe in U.S. treasury bill prices. Even the Reitz experiment, with its extreme state, has less than half the variability of the forward risk premium, with ten times the mean, as U.S. treasury bill data.

\section{Final remarks}

We have examined the term structure of interest rates from the perspective of general-equilibrium asset pricing and found that the standard representative agent model fails to account for the sign or the magnitude of 
risk premiums on forward contracts and holding-period returns on multiperiod bonds. This failure is robust to small modifications of the theory and to reinterpretations of the data suggested by sampling variability and aggregation over time. These discrepancies between theory and data have the same flavor as work by Mehra and Prescott (1985) on the average excess return of equity over bonds. Both emphasize differences in the mean values of risk premiums between observed asset prices and prices derived from a widely-used theoretical economy.

We also show that the theoretical economy cannot account for the variability of risk premiums. It fails, in particular, to account for the time variation in risk premiums implied by rejections of the expectations hypothesis with U.S. treasury bill data: regressions with artificial data, produced by simulating our theoretical economy, invariably accept the expectations hypothesis. This happens even when we relax the strict mapping between the data and the theoretical economy, and use parameter values that are inconsistent with other evidence. A large body of empirical work suggests that risk premiums on a variety of assets vary in systematic ways over time. Our work contributes to the increasingly strong evidence that such variation is not explicable in this class of theoretical models. Both sets of results, on the mean and variability of risk premiums, add to the growing list of empirical deficiencies of the representative agent model of asset pricing.

Finally, we think the artificial-economy approach, which has the same flavor as Tauchen's (1986) Monte Carlo study, is a useful one for bringing theory and econometric work together. It highlights the empirical content of the theory and provides a natural proving ground for econometric estimators and test statistics. 


\section{References}

D. Backus and P. Kehoe, "Trade and exchange rates in a dynamic competitive economy," Federal Reserve Bank of Minneapolis Working Paper 348, April 1987.

E. Barton, F. David, and E. Fix, "Persistence in a chain of multiple events when there is simple persistence," Biometrika, 49 (1962), 351-357.

D. Breeden, "An intertemporal asset pricing model with stochastic consumption and investment opportunities," Journal of Financial Economics, 7 (September 1979), 265-296.

W. Brock, "Asset prices in a production economy." In The economics of information and uncertainty, ed. J.J. McCal1, Chicago: University of Chicago Press, 1982.

S. Brown and P. Dybvig, "Empirical implications of the Cox, Ingersoll, Ross theory of the term structure of interest rates," Journal of Finance, 41 (July 1986), 617-630.

G. Constantinides, "Habit formation: a resolution of the equity premium puzzle," Working Paper, University of Chicago, December 1988.

J. Cox, J. Ingersoll, and S. Ross, "A theory of the term structure of interest rates," Econometrica, 53 (March 1985), 385-407.

K. Dunn and K. Singleton, "Modeling the term structure of interest rates under nonseparable utility and durability of goods, "Journal of Financial Economics, 17 (September 1986), 27-55.

R. Engle, "Autoregressive conditional heteroskedasticity with estimates of the variance of U.K. inflation, "Econometrica, 50 (July 1982), 987-1008.

R. Engle, D. Lilien, and R. Robins, "Estimating time-varying risk premia in the term structure: the ARCH-M model," Econometrica, 55 (March 1987), 391-407.

L. Epstein and S. Zin, "Substitution, risk aversion and the temporal behavior of consumption and asset returns: a theoretical framework," Working Paper, University of Toronto and Queen's University, 1989a; forthcoming Econometrica.

L. Epstein and S. Zin, "Substitution, risk aversion and the temporal behavior of consumption and asset returns: an empirical analysis," Working Paper, University of Toronto and Queen's University, $1989 \mathrm{~b}$.

L. Ermini, "Some new evidence on the timing of consumption decisions and on their generating process," Working Paper, University of Sydney, March 1988.

E. Fama, "Forward rates as predictors of future spot rates," Journal of Financial Economics, 3 (October 1976), 361-377. 
E. Fama, "The information in the term structure," Journal of Financial Economics, 13 (1984), 509-528.

W. Feller, An introduction to probability theory and its applications, volume 1 (third edition), New York: Wiley and Sons, 1968.

M. Gibbons and K. Ramaswamy, "The term structure of interest rates: empirical evidence," Working Paper, Stanford, December 1986.

S. Grossman, A. Melino, and R. Shiller, "Estimating the continuous time consumption based asset pricing model," Journal of Business and Economic Statistics, 5 (July 1987), 315-327.

L. Hansen and R. Jagannathan, "Using asset market data to restrict the volatility of intertemporal marginal rates of substitution," Working Paper, April 1988.

L. Hansen and $K$. Singleton, "Generalized instrumental variables estimation of nonlinear rational expectations models, "Econometrica, 50 (September 1982), 1269-1286.

L. Hansen and K. Singleton, "Stochastic consumption, risk aversion, and the temporal behavior of asset returns, " Journal of Political Economy, 91 (April 1983), 249-265.

J. Heaton, "The interaction between time-nonseparable preferences and time aggregation," Working Paper, University of Chicago, November 1988.

D. Isaacson and R. Madsen, Markov chains: theory and applications, New York: Wiley, 1976.

R. Lucas, "Asset prices in an exchange economy," Econometrica, 46 (November $1978), 1429-1445$.

R. Lucas, "Equilibrium in a pure currency economy," in J. Kareken and N. Wallace, eds., Models of monetary economies, Minneapolis: Federal Reserve Bank, 1980.

R. Merton, "An intertemporal capital asset pricing model," Econometrica, 41 (September 1973), 867-887.

R. Mehra and E. Prescott, "The equity premium: a puzzle, "Journal of Monetary Economics, 15 (March 1985), 145-161.

A. Melino, "The term structure of interest rates: evidence and theory," Journal of Economic Surveys, forthcoming, 1987.

W. Newey and K. West, "A simple positive semi-definite, heteroskedasticity and autocorrelation consistent covariance matrix, "Econometrica, 55 (May 1987), 703-708.

T. Reitz, "The equity premium: a solution," Journal of Monetary Economics, 22 (1988), 117-131. 
R. Roll, The behaviour of interest rates, New York: Basic Books, 1970.

T. Sargent, Dynamic macroeconomic theory, Cambridge: Harvard University Press, 1987.

R. Shiller, J. Campbell, and K. Schoenholtz, "Forward rates and future policy: interpreting the term structure of interest rates, "Brookings Papers on Economic Activity, 1:1983, 173-217.

R. Shiller and J. H. McCulloch, "The term structure of interest rates, " NBER Working Paper No. 2341, August 1987.

R. Stambaugh, "The information in forward rates: implications for models of the term structure," Working Paper, Chicago, November 1986.

R. Startz, "Do forecast errors or term premia really make the difference between long and short rates?" Journal of Financial Economics, 10 (November 1982), 323-329.

G. Tauchen, "Statistical properties of GMM estimates of structural parameters using financial market data," Journal of Business and Economic Statistics, 4 (October 1986), 397-425.

H. White, "A heteroskedasticity-consistent covariance matrix estimator and a direct test for heteroskedasticity," Econometrica, 48 (May 1980), 817-838. 
Table 2.1

TREASURY BILL PRICES AND YIELDS: SELECTED STATISTICS

Variable:

I. $1959: 2-1986: 2$ $q_{2 t}$

mean

st. deviation

auto-corr.

II. 1959:2 - 1972: 4

$q_{1 t}$

$\begin{array}{ccc}0.98432 & 0.96749 & 0.98285 \\ (0.0021) & (0.0041) & (0.0021) \\ 0.00757 & 0.01489 & 0.00769 \\ (0.0014) & (0.0026) & (0.0013) \\ 0.91 & 0.91 & 0.90 \\ (0.0421) & (0.0451) & (0.0486)\end{array}$

mean

st. deviation

auto-corr.

0.98953

(0.0011)

0.00334

(0.0006)

0.89

$(0.0515)$

0.97790

$(0.0022)$

0.00670

(0.0013)

0.88

(0.0546) $f_{1 t}$

$q_{1 t+1}-f_{1 t} \quad h_{2 t}-h_{1 t}$

III. 1973: 1 - 1986: 2

$\begin{array}{cccccc}\text { mean } & 0.97902 & 0.95690 & 0.97736 & 0.00171 & 0.00181 \\ & (0.0021) & (0.0041) & (0.0020) & (0.0006) & (0.0006) \\ \text { st. deviation } & 0.00697 & 0.01339 & 0.00687 & 0.00475 & 0.00506 \\ & (0.0011) & (0.0021) & (0.0011) & (0.0010) & (0.0011) \\ \text { auto-corr. } & 0.80 & 0.80 & 0.78 & -0.12 & -0.12 \\ & (0.0798) & (0.0897) & (0.0997) & (0.1423) & (0.1424)\end{array}$

Notes: Numbers in parentheses are Newey-West (1987) standard errors, computed by GMM using four lags of the autocorrelation function. Bill prices and returns were computed from monthly forward rates in the 6-month Fama file of the 1987 CRSP tape. 
Table 2.2

REGRESSIONS WITH U.S. TREASURY BILL PRICES AND YIELDS

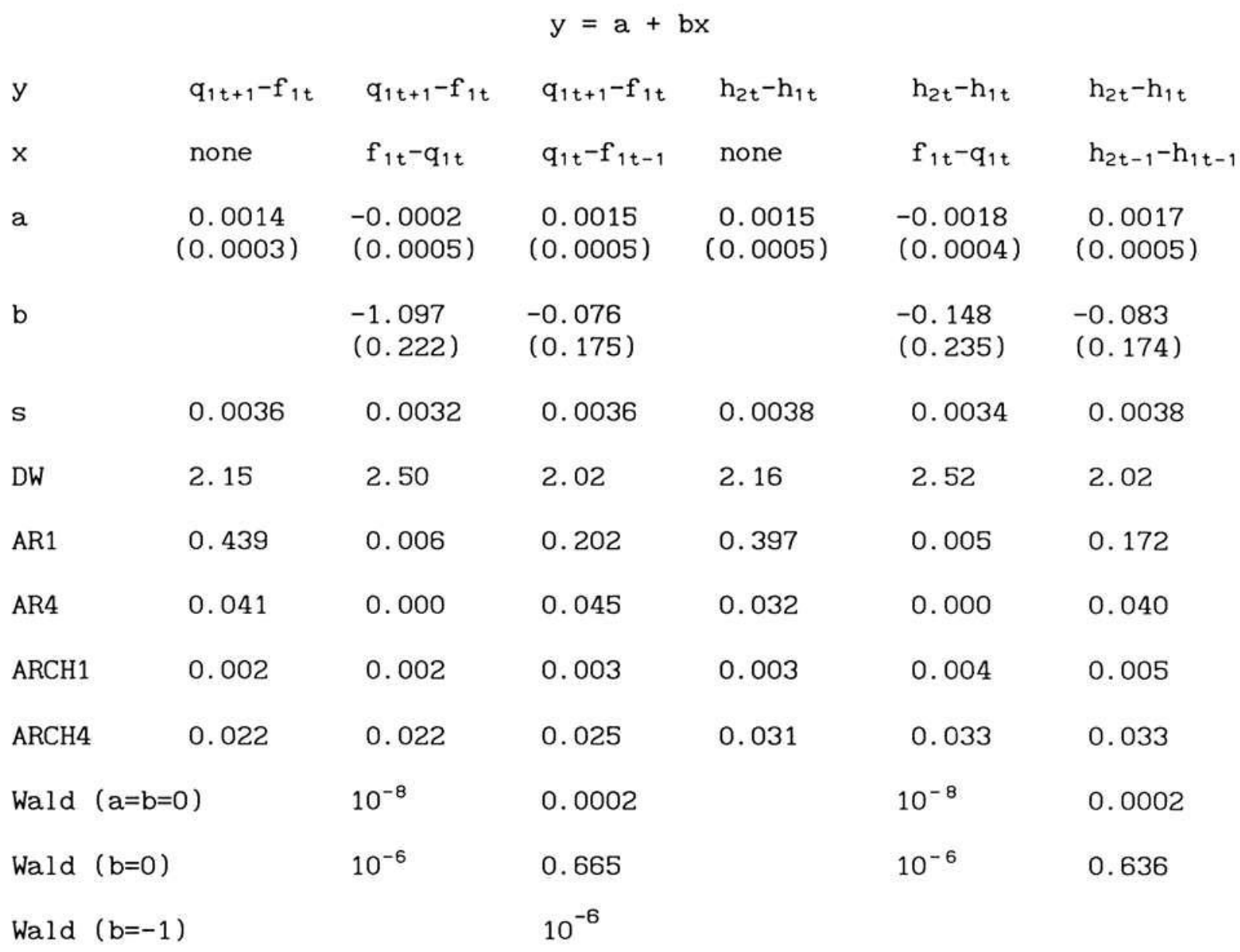

Notes: Data from the CRSP tape, 1959:3 to 1986:2 (108 observations). Numbers in parentheses are heteroskedasticity-consistent standard errors, $s$ is the estimated standard error of the regression, DW is the Durbin-Watson statistic, and ARn and ARCHn are marginal significance levels from tests for serial correlation and autoregressive conditional heteroskedasticity of order $n$. Wald is the marginal significance level for a Wald test of the indicated hypothesis based on a heteroskedasticity-consistent covariance matrix est imator. 
Table 4.1

PRICING FORMULAS FOR THE TWO-STATE EXAMPLE

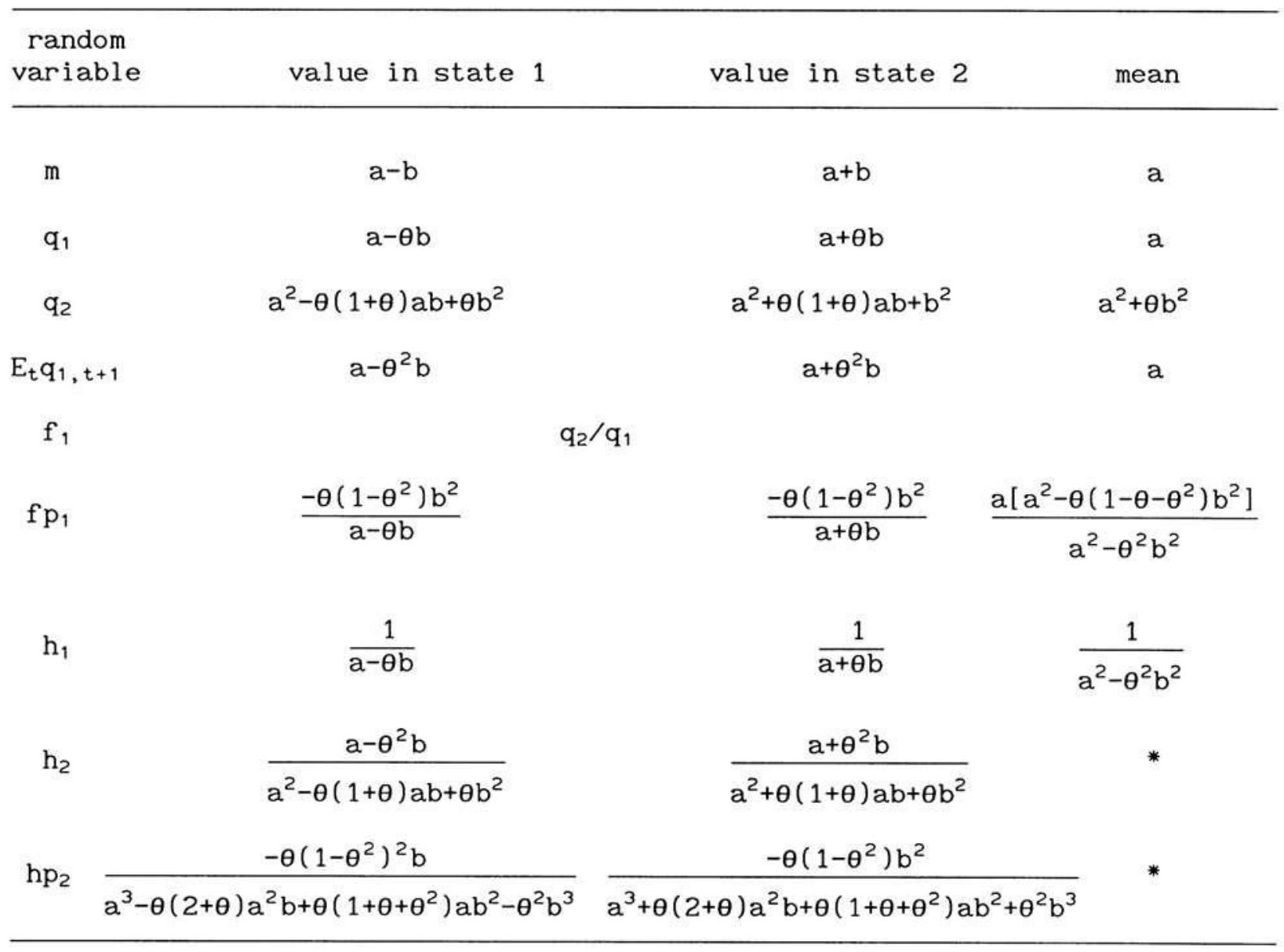

* These expressions are averages of the variable's value in the two states. 
Table 4.2

PER CAPITA CONSUMPTION AND PRICES: SELECTED STATISTICS

Per Capita Consumption Growth $\left(x_{t}\right)$

I. $1950: 1-1986: 2$

Total Services Nondurables Durables

$\begin{array}{ccccc}\text { mean } & 1.0053 & 1.0065 & 1.0032 & 1.0087 \\ & (0.0008) & (0.0005) & (0.0007) & (0.0024) \\ \text { st. deviation } & 0.0083 & 0.0053 & 0.0084 & 0.0426 \\ & (0.0010) & (0.0004) & (0.0008) & (0.0068) \\ \text { auto-corr. } & 0.07 & 0.06 & 0.08 & -0.09 \\ & (0.1441) & (0.0659) & (0.1569) & (0.0909)\end{array}$

II. 1959: $2-1972: 4$

$\begin{array}{ccccc}\text { mean } & 1.0068 & 1.0080 & 1.0043 & 1.0120 \\ & (0.0011) & (0.0006) & (0.0012) & (0.0043) \\ \text { st. deviation } & 0.0064 & 0.0043 & 0.0072 & 0.0311 \\ & (0.0005) & (0.0005) & (0.0007) & (0.0037) \\ \text { auto-corr. } & 0.13 & -0.01 & 0.19 & -0.12 \\ & (0.0877) & (0.1431) & (0.0956) & (0.1445)\end{array}$

III. 1973: 1 - 1986: 2

$\begin{array}{ccccc}\text { mean } & 1.0043 & 1.0052 & 1.0022 & 1.0079 \\ & (0.0016) & (0.0008) & (0.0016) & (0.0057) \\ \text { st. deviation } & 0.0080 & 0.0049 & 0.0083 & 0.0372 \\ & (0.0009) & (0.0005) & (0.0010) & (0.0042) \\ \text { auto-corr. } & 0.22 & -0.08 & 0.31 & -0.07 \\ & (0.0546) & (0.0714) & (0.0791) & (0.1058)\end{array}$

Price Level Growth $\left(p_{t} / p_{t-1}\right)$

I. 1950: $1-1986: 2$

Total Services Nondurables Durables

$\begin{array}{ccccc}\text { mean } & 1.0103 & 1.0122 & 1.0094 & 1.0071 \\ & (0.0017) & (0.0016) & (0.0021) & (0.0016) \\ \text { st. deviation } & 0.0080 & 0.0065 & 0.0108 & 0.0123 \\ & (0.0009) & (0.0008) & (0.0014) & (0.0019) \\ \text { auto-corr. } & 0.60 & 0.83 & 0.65 & 0.08 \\ & (0.1956) & (0.0484) & (0.0800) & (0.1596)\end{array}$

II. $1959: 2-1972: 4$

$\begin{array}{ccccc}\text { mean } & 1.0071 & 1.0084 & 1.0066 & 1.0042 \\ & (0.0011) & (0.0012) & (0.0011) & (0.0010) \\ \text { st. deviation } & 0.0038 & 0.0041 & 0.0046 & 0.0070 \\ & (0.0002) & (0.0004) & (0.0003) & (0.0008) \\ \text { auto-corr. } & 0.65 & 0.66 & 0.34 & -0.04 \\ & (0.0972) & (0.0797) & (0.1185) & (0.1567)\end{array}$


Table 4.2 continued

III. 1973: 1 - 1986: 2

$\begin{array}{ccccc}\text { mean } & 1.0164 & 1.0183 & 1.0154 & 1.0119 \\ & (0.0021) & (0.0015) & (0.0035) & (0.0082) \\ \text { st. deviation } & 0.0072 & 0.0050 & 0.0129 & 0.0083 \\ & (0.0008) & (0.0007) & (0.0018) & (0.0012) \\ \text { auto-corr. } & 0.75 & 0.82 & 0.65 & 0.80 \\ & (0.0621) & (0.0542) & (0.0521) & (0.0760)\end{array}$

Nominal Marginal Rates of Substitution $\left(n_{t}\right)$
$\alpha=2$
$\alpha=5$
$\alpha=10$
$\alpha=20$

I. 1950: 1 - 1986:2

$\begin{array}{ccccc}\text { mean } & 0.9900 & 0.9900 & 0.9900 & 0.9900 \\ & (0.0019) & (0.0037) & (0.0075) & (0.0160) \\ \text { st. deviation } & 0.0177 & 0.0415 & 0.0837 & 0.1745 \\ & (0.0029) & (0.0059) & (0.0113) & (0.0224) \\ \text { auto-corr. } & -0.06 & -0.02 & 0.01 & 0.02 \\ & (0.2023) & (0.1649) & (0.1536) & (0.1452)\end{array}$

II. 1959:2 -1972: 4

$\begin{array}{ccccc}\text { mean } & 0.9900 & 0.9900 & 0.9900 & 0.9900 \\ & (0.0025) & (0.0058) & (0.0113) & (0.0225) \\ \text { st. deviation } & 0.0131 & 0.0317 & 0.0630 & 0.1260 \\ & (0.0013) & (0.0029) & (0.0056) & (0.0117) \\ \text { auto-corr. } & 0.21 & 0.15 & 0.13 & 0.12 \\ & (0.1137) & (0.0481) & (0.0947) & (0.0952)\end{array}$

III. 1973: 1 - 1986: 2

$\begin{array}{ccccc}\text { mean } & 0.9900 & 0.9900 & 0.9900 & 0.9900 \\ & (0.0021) & (0.0067) & (0.0150) & (0.0327) \\ \text { st. deviation } & 0.0139 & 0.0375 & 0.0797 & 0.1716 \\ & (0.0016) & (0.0047) & (0.0106) & (0.0261) \\ \text { auto-corr. } & 0.00 & 0.11 & 0.16 & 0.17 \\ & (0.0723) & (0.0544) & (0.0560) & (0.0561)\end{array}$

Notes: Numbers in parentheses are Newey-West standard errors. Consumption, price level, and population data are from the 1987 CITIBASE tape, series GC82, GCS82, GCN82, GCD82, GDC, GDCS, GDCN, GDCD, and POPRES. Nominal marginal rates of substitution were computed from GC82 and GDC. 
Table 5.1

TEST RESULTS FROM EXPERIMENT 1: SYMMETRIC EQUILIBRIUM DISTRIBUTION

Number of Rejections by 5 Percent Tests in One Thousand Replications

$$
\theta=-0.3 \quad \pi=(0.5,0.5) \quad \mathrm{n}=(0.9063,1.0737)
$$

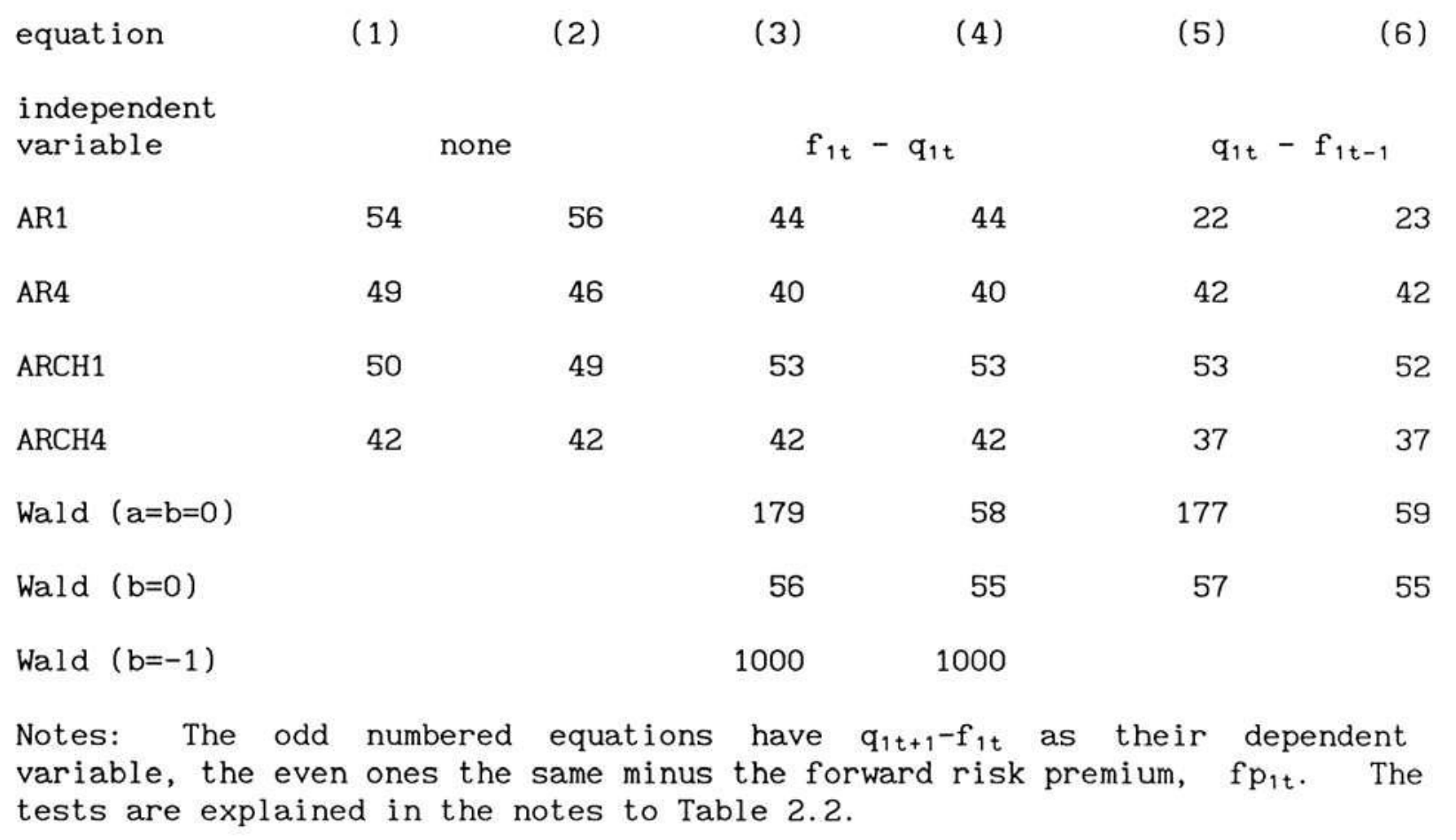


Table 5.2

SAMPLE REGRESSIONS FROM EXPERIMENT 1: SYMMETRIC EQUILIBRIUM DIST'N

$\mathrm{y}=\mathrm{a}+\mathrm{bx}$
$\theta=-.3 \quad \pi=(0.5,0.5) \quad \mathrm{n}=(0.9063,1.0730)$

\begin{tabular}{|c|c|c|c|c|c|c|}
\hline equation & (1) & (2) & (3) & (4) & (5) & (6) \\
\hline$x$ & \multicolumn{2}{|c|}{ none } & \multicolumn{2}{|c|}{$f_{1 t}-q_{1 t}$} & \multicolumn{2}{|c|}{$q_{1 t}-f_{1 t-1}$} \\
\hline $\mathrm{a}$ & $\begin{array}{c}0.0029 \\
(0.0017)\end{array}$ & $\begin{array}{c}0.0010 \\
(0.0017)\end{array}$ & $\begin{array}{c}0.0029 \\
(0.0017)\end{array}$ & $\begin{array}{c}0.0009 \\
(0.0017)\end{array}$ & $\begin{array}{c}0.0029 \\
(0.0017)\end{array}$ & $\begin{array}{c}0.0009 \\
(0.0017)\end{array}$ \\
\hline b & & & $\begin{array}{l}-0.013 \\
(0.053)\end{array}$ & $\begin{array}{l}-0.015 \\
(0.052)\end{array}$ & $\begin{array}{c}0.014 \\
(0.071)\end{array}$ & $\begin{array}{c}0.016 \\
(0.071)\end{array}$ \\
\hline s & 0.0242 & 0.0242 & 0.0242 & 0.0242 & 0.0242 & 0.0242 \\
\hline DW & 1.98 & 1.97 & 2.01 & 2.01 & 2.01 & 2.01 \\
\hline AR1 & 0.934 & 0.913 & 0.601 & 0.601 & 0.198 & 0.196 \\
\hline AR4 & 0.904 & 0.901 & 0.818 & 0.818 & 0.597 & 0.595 \\
\hline ARCH1 & 0.555 & 0.556 & 0.543 & 0.543 & 0.542 & 0.542 \\
\hline ARCH4 & 0.394 & 0.395 & 0.386 & 0.386 & 0.399 & 0.401 \\
\hline Wald $(a=b=0)$ & & & 0.227 & 0.818 & 0.230 & 0.829 \\
\hline Wald $(b=0)$ & & & 0.801 & 0.781 & 0.840 & 0.823 \\
\hline Wald $(b=-1)$ & & & $10^{-10}$ & $10^{-10}$ & & \\
\hline
\end{tabular}

Notes: See Table 5.1. 
Table 5.3

TEST RESULTS FROM EXPERIMENT 2: ASYMMETRIC EQUILIBRIUM DISTRIBUTION

Number of Rejections by 5 Percent Tests in One Thousand Replications

$$
\theta=-0.3 \quad \pi=(0.6,0.4) \quad \mathrm{n}=(0.9216,1.0925)
$$

equation

(1)

(2)

(3)

(4)

(5)

independent

variable

none

AR1

40

AR4

48

ARCH1

478

299

ARCH4

Wald $(a=b=0)$

Wald $(b=0)$

Wald $(b=-1)$

Notes: See Table 5.1.

\begin{tabular}{rrrr}
\multicolumn{2}{r}{$f_{1 t}-q_{1 t}$} & \multicolumn{2}{c}{$q_{1 t}-f_{1 t-1}$} \\
54 & 54 & 43 & 43 \\
53 & 53 & 46 & 45 \\
479 & 479 & 474 & 476 \\
280 & 280 & 273 & 278 \\
195 & 66 & 197 & 64 \\
49 & 50 & 50 & 58 \\
1000 & 1000 & &
\end{tabular}


Table 5.4

SAMPLE REGRESSIONS FROM EXPERIMENT 2: ASYMMETRIC EQUILIBRIUM DIST'N

$$
\begin{gathered}
y=a+b x \\
\theta=-.3 \quad \pi=(0.6,0.4) \quad n=(0.8875,1.1438)
\end{gathered}
$$

\begin{tabular}{|c|c|c|c|c|c|c|}
\hline equation & (1) & (2) & (3) & (4) & (5) & (6) \\
\hline $\mathrm{x}$ & \multicolumn{2}{|c|}{ none } & \multicolumn{2}{|c|}{$f_{1 t}-q_{1 t}$} & \multicolumn{2}{|c|}{$q_{1 t}-f_{1 t-1}$} \\
\hline $\mathrm{a}$ & $\begin{array}{c}0.0050 \\
(0.0016)\end{array}$ & $\begin{array}{c}0.0030 \\
(0.0016)\end{array}$ & $\begin{array}{c}0.0050 \\
(0.0016)\end{array}$ & $\begin{array}{c}0.0031 \\
(0.0016)\end{array}$ & $\begin{array}{c}0.0051 \\
(0.0016)\end{array}$ & $\begin{array}{c}0.0032 \\
(0.0016)\end{array}$ \\
\hline $\mathrm{b}$ & & & $\begin{array}{c}0.016 \\
(0.046)\end{array}$ & $\begin{array}{c}0.024 \\
(0.046)\end{array}$ & $\begin{array}{l}-0.026 \\
(0.064)\end{array}$ & $\begin{array}{l}-0.038 \\
(0.064)\end{array}$ \\
\hline s & 0.0232 & 0.0232 & 0.0233 & 0.0233 & 0.0232 & 0.0233 \\
\hline DW & 2.06 & 2.08 & 2.02 & 2.02 & 2.01 & 2.01 \\
\hline AR1 & 0.652 & 0.539 & 0.616 & 0.616 & 0.268 & 0.270 \\
\hline AR4 & 0.972 & 0.957 & 0.969 & 0.969 & 0.839 & 0.840 \\
\hline ARCH1 & 0.0001 & 0.00004 & 0.0002 & 0.0002 & 0.0003 & 0.0002 \\
\hline $\mathrm{ARCH} 4$ & 0.0002 & 0.0004 & 0.0004 & 0.0004 & 0.0004 & 0.0004 \\
\hline Wald $(a=b=0)$ & & & 0.004 & 0.089 & 0.004 & 0.086 \\
\hline Wald $(b=0)$ & & & 0.791 & 0.596 & 0.732 & 0.552 \\
\hline Wald $(b=-1)$ & & & $10^{-10}$ & $10^{-10}$ & & \\
\hline
\end{tabular}

Notes: See Table 5.1. 
Table 5.5

TEST RESULTS FROM EXPERIMENT 3: UNUSUAL STATES

Number of Rejections by 5 Percent Tests in One Thousand Replications

$\mathrm{n}=(0.5,1.3,1.4)$

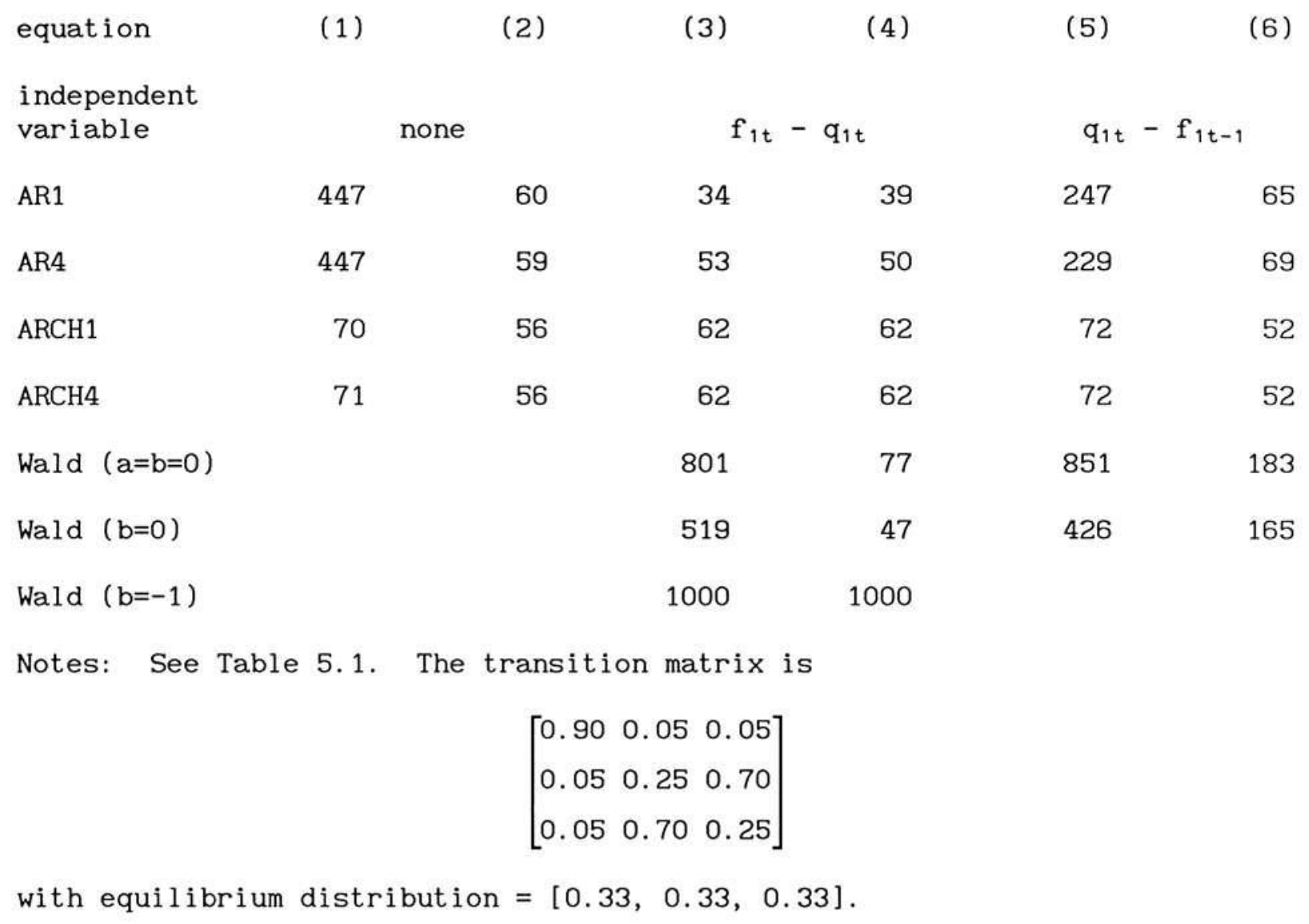


Table 5.6

SAMPLE REGRESSIONS FROM EXPERIMENT 3: UNUSUAL STATES

$$
\begin{gathered}
\mathrm{y}=\mathrm{a}+\mathrm{bx} \\
\mathrm{n}=(0.5,1.3,1.4)
\end{gathered}
$$

\begin{tabular}{|c|c|c|c|c|c|c|}
\hline equation & (1) & (2) & (3) & (4) & (5) & (6) \\
\hline $\mathrm{x}$ & \multicolumn{2}{|c|}{ none } & \multicolumn{2}{|c|}{$f_{1 t}-q_{1 t}$} & \multicolumn{2}{|c|}{$q_{1 t}-f_{1 t-1}$} \\
\hline $\mathrm{a}$ & $\begin{array}{l}-0.071 \\
(0.016)\end{array}$ & $\begin{array}{l}-0.015 \\
(0.016)\end{array}$ & $\begin{array}{l}-0.062 \\
(0.019)\end{array}$ & $\begin{array}{l}-0.031 \\
(0.019)\end{array}$ & $\begin{array}{l}-0.062 \\
(0.0159)\end{array}$ & $\begin{array}{c}0.014 \\
(0.016)\end{array}$ \\
\hline b & & & $\begin{array}{l}-0.138 \\
(0.167)\end{array}$ & $\begin{array}{c}0.230 \\
(0.168)\end{array}$ & $\begin{array}{c}0.134 \\
(0.030)\end{array}$ & $\begin{array}{c}0.026 \\
(0.032)\end{array}$ \\
\hline s & 0.2245 & 0.2249 & 0.2246 & 0.2243 & 0.2231 & 0.2253 \\
\hline DW & 1.73 & 1.90 & 1.80 & 1.81 & 1.98 & 1.95 \\
\hline AR1 & 0.066 & 0.492 & 0.077 & 0.086 & 0.600 & 0.040 \\
\hline AR4 & 0.354 & 0.226 & 0.432 & 0.393 & 0.892 & 0.225 \\
\hline ARCH1 & 0.104 & 0.101 & 0.102 & 0.104 & 0.064 & 0.092 \\
\hline ARCH4 & 0.551 & 0.544 & 0.549 & 0.548 & 0.429 & 0.520 \\
\hline Wald $(a=b=0)$ & & & 0.00003 & 0.236 & $10^{-9}$ & 0.447 \\
\hline Wald $(b=0)$ & & & 0.411 & 0.170 & $10^{-6}$ & 0.427 \\
\hline Wald $(b=-1)$ & & & $10^{-6}$ & $10^{-7}$ & & \\
\hline
\end{tabular}

Notes: See Tables 5.1 and 5.5. 
Table 5.7

MEANS AND STANDARD DEVIATIONS OF FORWARD RISK PREMIUMS

$\begin{array}{lcc}\text { Economy } & \text { mean } & \text { standard deviation } \\ \begin{array}{l}\text { United States } \\ \text { (estimated) }\end{array} & 0.0014 & 0.0016 \\ \begin{array}{l}\text { Experiment 1 } \\ \text { (symmetric eq dist) }\end{array} & 0.0019 & 0.00005 \\ \begin{array}{l}\text { Experiment 2 } \\ \text { (asymmetric eq dist) }\end{array} & 0.0019 & 0.0003 \\ \begin{array}{l}\text { Experiment 3 } \\ \text { (unusual states) }\end{array} & -0.0459 & 0.0342 \\ \begin{array}{l}\text { Experiment S1 } \\ \text { (extreme values) }\end{array} & 0.0108 & 0.0041 \\ \begin{array}{l}\text { Experiment S2 } \\ \text { (Reitz) }\end{array} & 0.0141 & 0.0008\end{array}$


Supplementary Table 1

TEST RESULTS FROM EXPERIMENT S1: EXTREME VALUES FOR $\alpha$ AND $\theta$ Number of Rejections by 5 Percent Tests in One Thousand Replications
$\theta=-0.5$
$\pi=(0.6,0.4)$
$\mathrm{n}=(0.8504,1.2002)$

equation

(1)

(2)

(3)

none

$f_{1 t}-q_{1 t}$

47

64

65

310

188

457

103

1000

Wald $(b=-1)$
(4)

(5)

$q_{1 t}-f_{1 t-1}$

39

56

236

141

457

80

59

1000
163

73

56

Notes: See Table 5.1. 


\section{Supplementary Table 2}

\section{TEST RESULTS FROM EXPERIMENT S2: THE REITZ ECONOMY}

Number of Rejections by 5 Percent Tests in One Thousand Replications

$$
\theta=-0.5
$$$$
\mathrm{n}=(1.1091,0.7012,116.18)
$$

$$
\text { equation }
$$

(1)

(2)

none

$$
\text { variable }
$$

AR1

AR4

ARCH1

ARCH4

Wald $(a=b=0)$

Wald $(b=0)$

Wald $(b=-1)$
(3)

(4)

$$
f_{1 t}-q_{1 t}
$$

51

55

58

52

53

71

46

63

54

1000

74

1000

85

1000
(5)

$$
q_{1 t}-f_{1 t-1}
$$

23

52

51

74

76

71

50

48

44

1000

57

84

54

Notes: See Table 5.1. 